\title{
Cell biology beyond the diffraction limit: near-field scanning optical microscopy
}

\author{
Frank de Lange ${ }^{1}$, Alessandra Cambi ${ }^{1}$, Richard Huijbens ${ }^{1}$, Bärbel de Bakker ${ }^{2}$, Wouter Rensen², \\ Maria Garcia-Parajo ${ }^{2}$, Niek van Hulst ${ }^{2}$ and Carl G. Figdor ${ }^{1, *}$ \\ ${ }^{1}$ Department of Tumor Immunology, University Medical Center Nijmegen, NCMLS/187 TIL, PO Box 9101, 6500HB Nijmegen, The Netherlands \\ ${ }^{2}$ Applied Optics Group, Faculty of Applied Physics and MESA+ Research Institute, University of Twente, PO Box 217, 7500AE Enschede, The \\ Netherlands \\ *Author for correspondence (e-mail: c.figdor@mailbox.kun.nl)
}

Journal of Cell Science 114, 4153-4160 (2001) @ The Company of Biologists Ltd

\section{Summary}

Throughout the years, fluorescence microscopy has proven to be an extremely versatile tool for cell biologists to study live cells. Its high sensitivity and non-invasiveness, together with the ever-growing spectrum of sophisticated fluorescent indicators, ensure that it will continue to have a prominent role in the future. A drawback of light microscopy is the fundamental limit of the attainable spatial resolution $\sim 250 \mathrm{~nm}$ - dictated by the laws of diffraction. The challenge to break this diffraction limit has led to the development of several novel imaging techniques. One of them, near-field scanning optical microscopy (NSOM), allows fluorescence imaging at a resolution of only a few tens of nanometers and, because of the extremely small near-field excitation volume, reduces background fluorescence from the cytoplasm to the extent that single-molecule detection sensitivity becomes within reach. NSOM allows detection of individual fluorescent proteins as part of multimolecular complexes on the surface of fixed cells, and similar results should be achievable under physiological conditions in the near future.

Key words: Super-resolution, Near-field scanning optical microscopy, Single-molecule detection, Distribution, Cell surface, Membrane, GFP

\section{Introduction}

Fluorescence microscopy has gained a firm position among the most important research tools in modern cell biology. It offers high chemically specific contrast, and is non-invasive, and sample handling is non-destructive and therefore allows the study of living cells. Moreover, optical detection is very fast, providing picosecond time resolution, and the very nature of light offers additional contrast mechanisms (e.g. based on polarization or phase discrimination) that yield additional information. Furthermore, imaging can be performed in three dimensions by multi-photon excitation, confocal detection or deconvolution techniques. Finally, a wide range of ultra-sensitive detectors - for example, cooled CCD (charge-coupled device) cameras and photon-counting devices - that make optical detection extremely sensitive, even down to the single-molecule level, are available.

The ability to tailor fluorescent fusion proteins, exploiting the strong autofluorescence of the green fluorescent protein (GFP) family (Patterson et al., 2001), has fueled interest in fluorescence microscopy even further. The most successful applications of these fluorescent proteins are in gene expression, protein targeting and trafficking, and proteinprotein interaction studies (Tsien, 1998; Lippincott-Schwartz et al., 2001). Employing various forms of these fluorescent proteins, in most cases using fluorescence resonance energy transfer (FRET) as a read-out (Wouters et al., 2001), highly potent cellular indicators for calcium (Miyawaki et al., 1997; Miyawaki et al., 1999), pH (Llopes et al., 1998), cyclic AMP (Zaccolo et al., 2000), cyclic GMP (Honda et al., 2001), caspases (Harpur, 2001) and small G protein activity (Mochizuki et al., 2001), among others, have been developed. The limit to the resolution that can be reached in optical imaging techniques is directly related to the wavelength of the light. This diffraction limit originates from the fact that it is impossible to focus light to a spot smaller than half its wavelength. In practice this means that the maximal resolution in optical microscopy is $250-300 \mathrm{~nm}$. Since a large body of evidence indicates that dynamic cell-signaling events start by oligomerization and interaction of individual proteins (i.e. on the molecular scale), the need for imaging techniques that have a higher resolution is growing. Traditionally, high-resolution cell biology (Table 1) is the arena of electron microscopy, which offers superb resolution but lacks the above-mentioned advantages of fluorescence microscopy. The advent of scanning probe microscopy (Table 1), and especially atomic force microscopy (AFM), in which an atomically sharp probe attached to a cantilever is scanned over the surface of interest, has made nanometer resolution also attainable on living cells (Hansma et al., 1994; Putman et al., 1994). However, although AFM produces a high-resolution topographical picture of the sample, it lacks chemical specificity. Hence, although individual molecules can be seen, their identities cannot be defined. This seriously limits the usefulness of AFM for high-resolution imaging on cells. Initially, this contrast problem was tackled by the use of immunogold-labeling approaches (Damjanovich et al., 1995; Neagu et al., 1994). A promising new way around the problem comes from work on the specific labeling of the AFM probe with biomolecules (e.g. with antibodies or ligands). This introduces a contrast mechanism based on specific interactions between the probe and certain types of molecule in the specimen (Willemsen et al., 2000). Other attempts to enhance AFM contrast involve the modification of the probe by fluorescent molecules, which introduces an optical contrast 
Table 1. High-resolution imaging in cell biology

\begin{tabular}{|c|c|c|c|c|c|}
\hline Type & & abtype & Remarks & Application & References \\
\hline Light microscopy & $\begin{array}{l}\text { Wide field, ph } \\
\text { differential il } \\
\text { contrast (DIC } \\
\text { Confocal lase } \\
\text { microscopy } \\
\text { Total internal } \\
\text { fluorescence } \\
\text { (evanescent } \\
\text { Reflection cor } \\
\text { interference } \\
\text { microscopy }\end{array}$ & $\begin{array}{l}\text { ase-contrast, } \\
\text { nterference } \\
\text { C), etc. } \\
\text { r scanning } \\
\text { (CLSM) } \\
\text { reflection } \\
\text { microscopy (TIRF) } \\
\text { wave microscopy) } \\
\text { trast microscopy: } \\
\text { reflection } \\
\text { (IRM) }\end{array}$ & $\begin{array}{l}\text { Max. resolution } 250 \mathrm{~nm} \\
\text { Spectral, polarization and } \\
\text { phase contrast } \\
\text { Relatively easy to do } \\
\text { Widely accessible } \\
\text { Non invasive } \\
\text { Possible on living cells } \\
\text { Dynamics; protein diffusion, } \\
\text { targeting and trafficking }\end{array}$ & $\begin{array}{l}\text { TIRF: cell-substrate contact } \\
\text { zone, tunable penetration depth } \\
\text { DIC: cell-substrate contacts, } \\
\text { focal adhesion } \\
\text { Intermolecular and intramolecular } \\
\text { dynamics by FRET } \\
\text { CLSM, FRAP } \\
\text { Various microscopy imaging } \\
\text { Single molecule imaging } \\
\text { (Table 2) }\end{array}$ & $\begin{array}{l}\text { Smilenov et al., } 1999 \text { (IRM) } \\
\text { Lippincott-Schwartz et al., } 2001 \\
\text { (FRAP) } \\
\text { Toomre and Manstein, } 2001 \\
\text { (TIRF) } \\
\text { Johns et al., } 2001 \text { (TIRF) } \\
\text { Richter et al., } 2000 \text { (IRM) }\end{array}$ \\
\hline Electron microscopy & $\begin{array}{l}\text { Scanning EM } \\
\text { Transmission } \\
\text { Scanning tran }\end{array}$ & $\begin{array}{l}\text { EM } \\
\text { smission EM }\end{array}$ & $\begin{array}{l}\text { Max. resolution } 0.1 \mathrm{~nm} \\
\text { Contrast based on density } \\
\text { Requires expert knowledge } \\
\text { Invasive } \\
\text { Not possible on living cells }\end{array}$ & $\begin{array}{l}\text { Cell surface } \\
\text { Cell sections } \\
\text { Immunogold labeling } \\
\text { Mass determination } \\
\text { Imaging of sub-molecular structure }\end{array}$ & $\begin{array}{l}\text { Allen et al., } 2000 \\
\text { Muller and Engel, } 2001\end{array}$ \\
\hline & NSOM/ PSTM & $\begin{array}{l}\text { Optical, sub- } \\
\text { wavelength optical } \\
\text { fiber probe }\end{array}$ & $\begin{array}{l}\text { NSOM: optical contrast } \\
\text { combined with topography } \\
\text { Optical resolution depending } \\
\text { on probe aperture diameter } \\
(20-120 \mathrm{~nm} \text { ) and probe- } \\
\text { sample distance (less than } \\
5-10 \mathrm{~nm} \text { ) } \\
\text { Possible on living cells } \\
\text { (see text) }\end{array}$ & See Tables 2 and 3 & See Tables 2 and 3 \\
\hline
\end{tabular}

mechanism (Vickery and Dunn, 2001). Currently, however, the combination of high-resolution scanning probe and fluorescence microscopy is the realm of another scanning probe technique: near-field scanning optical microscopy (NSOM).

\section{NSOM}

In NSOM, as in the case of AFM, a sharp probe physically scans the sample surface (Fig. 1). Besides topography, NSOM also generates optical images. A typical NSOM configuration is shown in Fig. 2. The practical feasibility of this kind of NSOM was first demonstrated by Pohl et al., immediately following the advent of scanning probe microscopy and in fact before the introduction of the AFM (Pohl et al., 1984). The most generally applied near-field optical probe consists of a small aperture, typically $20-120 \mathrm{~nm}$ in diameter (i.e. much smaller than the wavelength of the excitation light), at the end of a metal-coated tapered optical fiber* (Fig. 3A,B). This probe is the most critical element of the technique and is difficult to produce reliably and in large quantities (Van Hulst et al., 2000).

*Other types of probe exist; for example, aperture-less and non-metal-coated aperture type probes have been described. Applications of the former in biology have, to our knowledge, not yet been described; examples of the latter are reviewed below.
In fluorescence mode*, it serves as a constriction that funnels an incident light wave to dimensions that are substantially below the diffraction limit. This results in a light-source that has the size of the aperture. However, in contrast to common light sources such as lightbulbs and lasers, the light emitted by the probe is predominantly composed of evanescent waves rather than propagating waves. The intensity of the evanescent light decays exponentially and to insignificant levels $\sim 100 \mathrm{~nm}$ from the aperture. Effectively, the probe can excite fluorophores only within a layer of $<100 \mathrm{~nm}$ from the probe that is, in the 'near-field' region (Fig. 3B). Sample fluorescence can subsequently be collected by conventional optics (Fig. 2) and transformed into an optical image of the sample surface in which the resolution is now primarily dictated by the aperture dimensions rather than by the wavelength of the light.

Since the near-field intensity decays so rapidly with distance from the probe, for efficient excitation it is essential to have accurate control of the probe-sample distance during scanning. As in AFM, this can be accomplished by using a (force) feedback loop. However, in contrast to regular AFM, which

*Here, we focus on fluorescence-mode NSOM. Applications of transmission-type NSOM to biological systems have also been described; however, for these the reader is referred to Van Hulst and Moers (Van Hulst and Moers, 1996). 


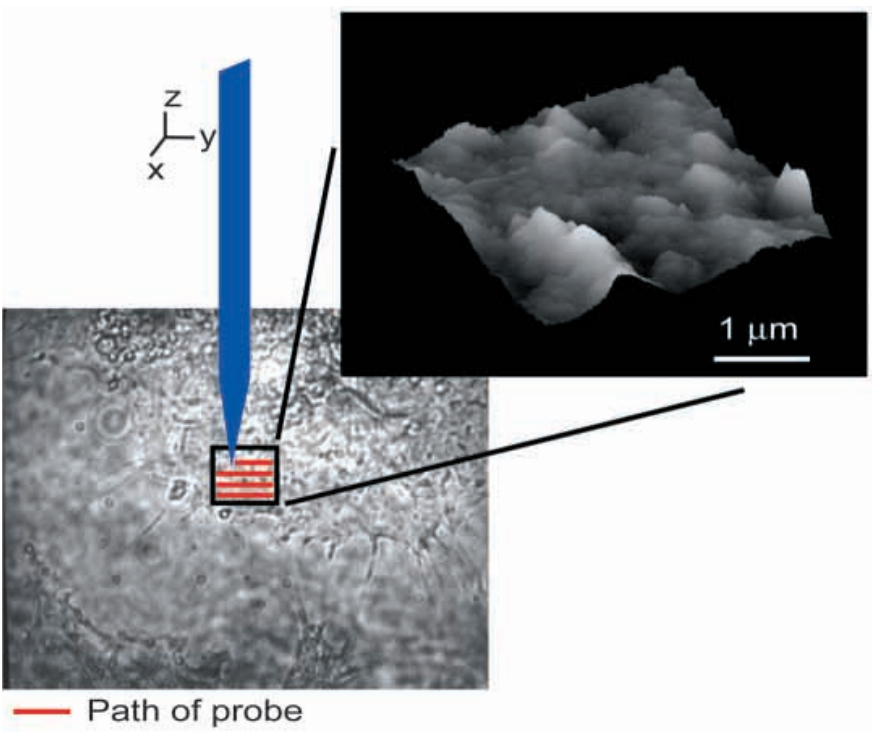

Fig. 1. The principle of scanning probe microscopy. In AFM and NSOM, a sharp probe is used to map the topographic features on the sample surface accurately. This is done by physically scanning the probe over the surface while maintaining a constant probe-sample distance by force feedback.

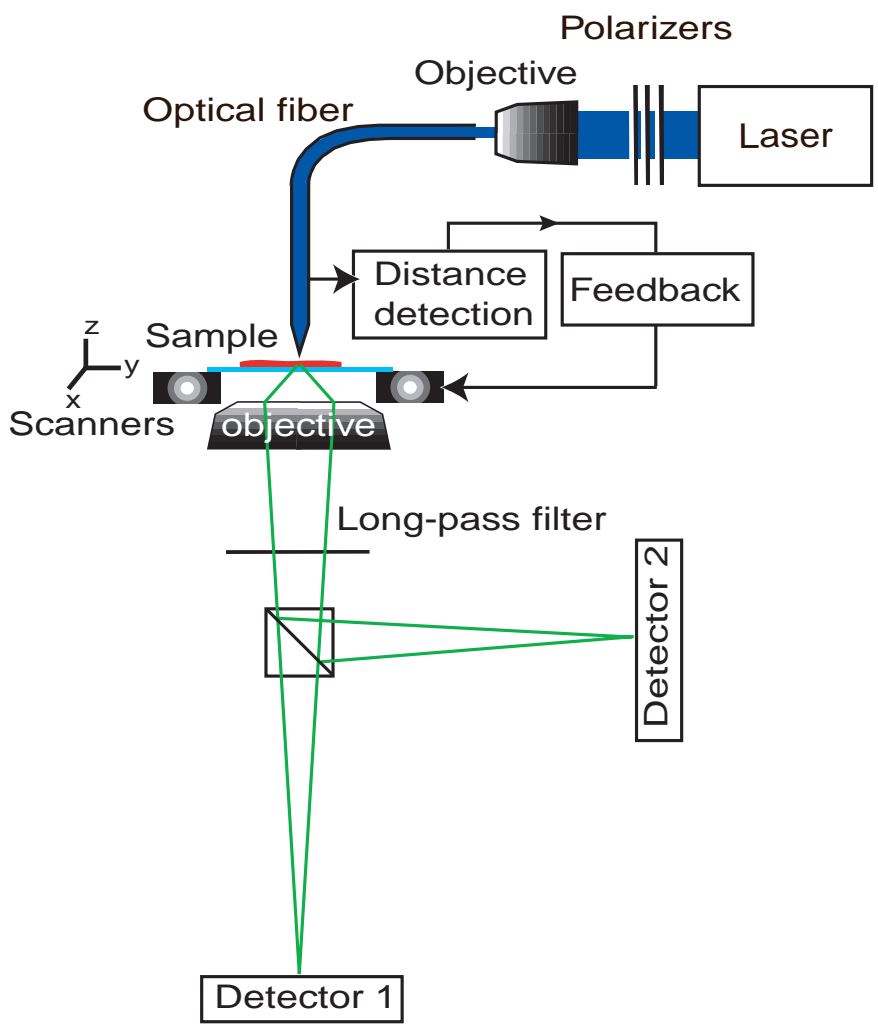

Fig. 2. Schematic lay out of a near-field scanning optical microscope. The NSOM probe is a tapered optical fiber (Fig. 3A). Laser light is coupled into the fiber and is used to excite fluorophores as the probe scans the sample surface. The probe-sample distance is maintained constant at $<10 \mathrm{~nm}$ during scanning by shear-force-based distance detection in combination with an electronic feedback system controlling the piezoelectric scan stage. Fluorescence is collected by a conventional inverted microscope. Dual-channel optical detection allows wavelength and/or polarization discrimination.

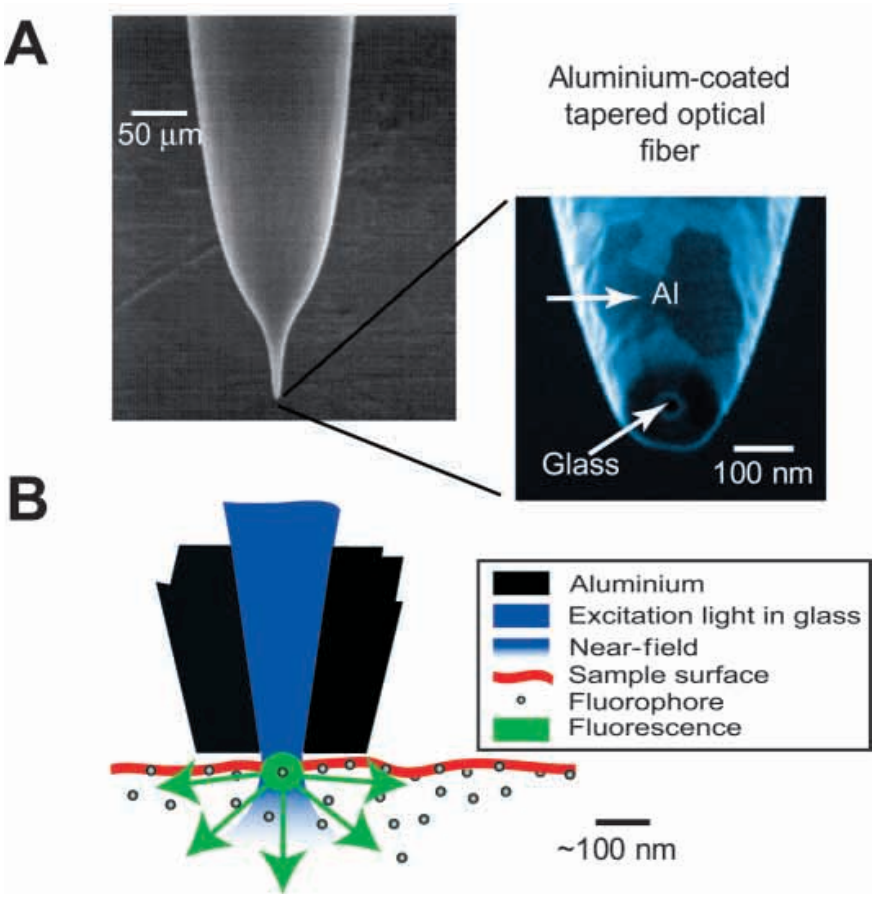

Fig. 3. The near-field optical probe. (A) An optical fiber is pulled to a final diameter of 20-120 nm and subsequently coated with aluminum. This coating serves to confine the light to the tip region. A subsequent etching step results in a flat and circular endpoint and aperture. The aperture functions as a miniature light source, and its diameter primarily determines the optical resolution of the microscope. (B) The principle of surface-specific excitation. The optical near-field generated at the aperture has significant intensity only in a layer of $<100 \mathrm{~nm}$ from the aperture; lower lying fluorophores are therefore not excited. Hence, background fluorescence is effectively suppressed. This forms the basis for the high optical detection sensitivity of this technique.

exploits the bending of a cantilever attached to the probe as a direct measure of the probe-sample interaction force, in NSOM an indirect method, based on shear-force damping, is commonly used. For this, the NSOM probe, or a piezoelectric tuning fork attached to it, is oscillated at its resonance frequency in a lateral vibrational mode (with a $<1 \mathrm{~nm}$ amplitude); when in proximity to the sample, shear-forces dampen this motion and induce measurable changes in the oscillation amplitude and phase. An electronic feedback system, controlling the probe-sample distance directly through the piezoelectric scan stage, is subsequently used to maintain a constant oscillation amplitude/phase during scanning. In this way, a constant probe-sample distance of $<10 \mathrm{~nm}$ is realized (Fig. 2). The feedback signal itself, as in AFM, is used to generate a topographic map of the sample surface (Fig. 1). Of course, unique to NSOM is the fact that a corresponding fluorescence map is simultaneously generated.

The optical detection sensitivity of NSOM depends largely on the extremely small excitation/detection volume set by the aperture dimensions as well as the depth of penetration of the near-field into the specimen. Together, these properties effectively reduce background fluorescence and thereby enhance detection sensitivity. Betzig and Chichester exploited this eight years ago, providing the first observation of singlemolecule fluorescence under ambient conditions (Betzig and 
Table 2. Single-molecule fluorescence microscopy

\begin{tabular}{|c|c|c|c|c|c|c|}
\hline Technique & Application & Living cells? & Resolution & $\begin{array}{l}\text { Localization } \\
\text { accuracy }\end{array}$ & $\begin{array}{l}\text { Max. no. of } \\
\text { dyes per } \mu \mathrm{m}^{2}\end{array}$ & References \\
\hline Wide-field & $\begin{array}{l}\text { Single molecule diffusion in cell } \\
\text { and artificial membranes }\end{array}$ & Yes & $<250 \mathrm{~nm}$ & $<<40 \mathrm{~nm}$ & $<10$ & $\begin{array}{l}\text { Schmidt et al., } 1996 \\
\text { Schütz et al., } 2000 \\
\text { Harms et al., } 2001\end{array}$ \\
\hline Confocal & $\begin{array}{l}\text { Enzyme/DNA conformational } \\
\text { dynamics studied by single pair } \\
\text { FRET } \\
\text { Single dye photophysics }\end{array}$ & Yes & $\sim 250 \mathrm{~nm}$ & $\sim 40 \mathrm{~nm}$ & 10 & $\begin{array}{l}\text { Weiss, } 1999 \\
\text { Ha et al., } 1999 \\
\text { Moerner et al., } 1999 \\
\text { Van Oijen et al., } 1999 \\
\text { Deniz et al., } 1999 \\
\text { Talaga et al., } 2000\end{array}$ \\
\hline TIRF & $\begin{array}{l}\text { Cell-substrate contact zone } \\
\text { Inter- and intramolecular interactions } \\
\text { and dynamics; FRET } \\
\text { Single molecule diffusion }\end{array}$ & Yes & $\sim 250 \mathrm{~nm}$ & $\sim 40 \mathrm{~nm}$ & 10 & $\begin{array}{l}\text { Ishijima et al., } 1998 \\
\text { Kitamura et al., } 1999 \\
\text { Ishii and Yanagida, } 2000 \\
\text { Sako et al., } 2000\end{array}$ \\
\hline NSOM & $\begin{array}{l}\text { Single GFP/dye photophysics } \\
\text { DNA conformation studied by single } \\
\text { pair FRET } \\
\text { Single molecule spectroscopy } \\
\text { Lifetimes of single dyes }\end{array}$ & Not yet & $>50 \mathrm{~nm}$ possible & $>6 \mathrm{~nm}$ & 100 & $\begin{array}{l}\text { Betzig et al., } 1993 \\
\text { Xie and Dunn, } 1994 \\
\text { Ambrose et al., } 1994 \\
\text { Ha et al., } 1996 \\
\text { Ruiter et al., } 1997 \\
\text { Garcia-Parajo et al., } 1999 \\
\text { Garcia-Parajo et al., } 2000 \\
\text { Van Hulst et al., } 2000\end{array}$ \\
\hline
\end{tabular}

Chichester, 1993). Furthermore, employing the polarization characteristics of the near-field, they showed that it is possible to determine the full spatial orientation of fluorescent molecules by making use of polarization-sensitive fluorescence detection (see below). Subsequently, developments in instrumentation that greatly improved signal-to-background ratios allowed single-molecule fluorescence studies to come within reach of far-field methods such as total internal reflection, confocal and bright-field microscopy (see Table 2). The advantage of singlemolecule studies is that they provide a way to monitor timedependent processes and reaction pathways in non-equilibrated systems, which reveals the distribution of a given molecular property instead of a statistical average. This has already led to a whole new frontier in science, its applications ranging from basic photo-physics and material research to biology (Frontiers in Chemistry, 1999; Xie and Lu, 1999; Sako et al., 2000; Ishii and Yanagida, 2000). Nowadays almost all experiments in this field use far-field methods, mainly because they are relatively easy to use. However, the obvious disadvantage is that, because of the diffraction-limited system response, only scarcely labeled samples can be studied, but, in biology, molecules are usually present in close proximity. The combination of topographical information, optical super-resolution and single-molecule detection sensitivity therefore makes NSOM a unique tool for biological applications.

\section{Biological applications of NSOM}

A large body of evidence indicates that (induced) lateral organization in the plasma membrane is crucial to trigger cell signaling. One example is the early events in signal transduction by the epidermal growth factor receptor (EGFR), dimerization and phosphorylation following EGF binding (Yarden and Schlessinger, 1987a; Yarden and Schlessinger, 1987b). Another is the formation of focal adhesions, large signaling complexes involved in cell-adhesion and migration, and their equivalent on leukocytes, 'adhesisomes'. An important first step in the assembly of such complexes appears to be clustering of integrin receptors (Balaban et al., 2001; Van Kooyk and Figdor, 2000). Understanding of the signaling capacities of these adhesion sites requires insight into their assembly and spatial organization on the molecular level. The concept of 'lipid rafts' provides yet another level of organization in the plasma membrane at the submicroscopic level (Simons and Toomre, 2000). So far, these phenomena have been studied by use of far-field optical techniques, such as TIRF, IRM and confocal microscopy (Table 1). Clearly, higher-resolution/sensitivity would produce a major step forward in our understanding of the underlying mechanisms.

So far, most applications of NSOM in biology involve systems that are more or less isolated (Table 3) - for example, studies on fluorescently labeled chromosomes (Moers et al., 1996), DNA (Ha et al., 1996; Garcia-Parajo et al., 1998) and purified fluorescent proteins (Garcia-Parajo et al., 1999; Garcia-Parajo et al., 2000). Cell biological studies include fluorescence imaging of cytoskeletal components in 3T3 fibroblasts (Betzig et al., 1993) and colocalization of malarial and host skeletal proteins on malaria-infected erythrocytes (Enderle et al., 1997). Furthermore, sub-wavelength-sized membrane patches in human skin fibroblasts (Hwang et al., 1998) and activation-dependent receptor clustering on a human breast carcinoma cell line have also been studied (Nagy et al., 1999). Although these studies show a resolution well beyond that of a confocal microscope, to the best of our knowledge no study showing single-molecule detection sensitivity in a cell membrane by NSOM has been reported.

\section{Single-molecule detection on cells by NSOM}

To demonstrate the potential of near-field optical microscopy to study the distribution and orientation of cell surface 
Table 3. Biological applications of NSOM

\begin{tabular}{|c|c|c|c|c|c|}
\hline System & Mode & Type of analysis & Air & Liquid & References \\
\hline \multirow[t]{2}{*}{ Mouse fibroblast } & $\begin{array}{l}\text { Aperture type, } \\
\text { metal-coated fiber }\end{array}$ & $\begin{array}{l}\text { High-resolution imaging of actin } \\
\text { cytoskeleton in a cell protrusion }\end{array}$ & + & & Betzig et al., 1993 \\
\hline & $\begin{array}{l}\text { Shared aperture (collection mode), } \\
\text { non-coated probe }\end{array}$ & $\begin{array}{l}\text { Study on the localized interactions } \\
\text { between labeled conA molecules on } \\
\text { the surface of } 3 \text { T3 fibroblasts (FRET) }\end{array}$ & + & & Kirsch et al., 1999 \\
\hline DNA & Aperture type, metal-coated fiber & $\begin{array}{l}\text { DNA conformation probed using } \\
\text { dual-labeled oligomers (FRET) }\end{array}$ & + & & Ha et al., 1996 \\
\hline Human etythrocytes & Aperture type, metal-coated fiber & $\begin{array}{l}\text { Imaging of molecular colocalization } \\
\text { of malarial and host skeletal protein } \\
\text { on the cell membrane }\end{array}$ & + & & Enderle et al., 1997 \\
\hline Human skin fibrobast & Aperture type, metal-coated fiber & Investigation of cell membrane domains & + & + & Hwang et al., 1998 \\
\hline $\begin{array}{l}\text { Human breast tumor } \\
\text { cell }\end{array}$ & $\begin{array}{l}\text { Shared aperture (collection mode), } \\
\text { non-coated probe }\end{array}$ & $\begin{array}{l}\text { Detection and characterization of ErbB2 } \\
\text { clustering on the surface of quiescent } \\
\text { and activated cells }\end{array}$ & & & Nagy et al., 1999 \\
\hline Chromosome & Aperture type, metal-coated fiber & $\begin{array}{l}\text { High-resolution fluorescence in situ } \\
\text { hybridization }\end{array}$ & + & & $\begin{array}{l}\text { Van Hulst and Moers, } 1996 \\
\text { Hausmann et al., } 2001\end{array}$ \\
\hline
\end{tabular}

molecules, we investigated the distribution of LFA-1 $(\alpha \mathrm{L} / \beta 2$ integrin) molecules in murine fibroblasts. Fig. 4A shows a bright-field image as well as a near-field 'zoom-in' on the surface of a fixed and critical-point-dried L-cell (a mouse fibroblast cell line) expressing human GFP-tagged LFA-1*.

The near-field image shows a number of interesting findings. First individual fluorescent LFA-1 molecules (circles, squares and hexagon) as well as clusters of molecules can be recognized (arrows). Secondly, one can observe different orientations of the GFP linked to the LFA-1 $\beta$ chain, as determined by the polarization of the emitted light. The latter is of great value to discriminate LFA-1 molecules that are closer than half the tip-aperture diameter. Although these molecules cannot be discriminated by their fluorescence intensity signal, the difference in polarization contrast reveals them as separate entities (Van Hulst et al., 2000). Finally, the figure shows examples of photodissociation (circles) and the characteristic blinking behavior (squares and inset) of single molecule GFP fluorescence (Garcia-Parajo et al., 2000). Fig. $4 \mathrm{~B}$ depicts a line trace through the feature marked with a hexagon, showing a signal-to-background ratio of 7 and a 90 $\mathrm{nm}$ full width at half maximum (FWHM; arrows). From the latter, one can calculate that the lateral resolution in this image is $\sim 40 \mathrm{~nm}$ (Van Hulst et al., 2000). Taken together, the discrete photo-behavior, defined polarization characteristics and the number of counts per spot provide compelling evidence that individual molecules can be recognized on the cell surface by NSOM.

\section{Single-molecule localization accuracy by NSOM as compared to other microscopical techniques}

A direct comparison between the localization accuracy of cell membrane receptor molecules of NSOM and far-field imaging techniques is instructive (Table 2). In confocal fluorescence studies, using a 1.3 numerical aperture objective, two groups have reported a lateral positioning accuracy of 30-40 nm (Schmidt et al., 1996; Van Oijen et al., 1998). For $10^{4}$ collected photons and a $70 \mathrm{~nm}$ aperture probe, NSOM can be calculated to attain a localization accuracy of $6 \mathrm{~nm}$ - a level comparable to the FRET interaction-distance regime $(0-10 \mathrm{~nm})$. Given a

*Sample preparation will be detailed elsewhere. resolution of $\sim 50 \mathrm{~nm}$, NSOM should allow independent observation of several hundreds of molecules $/ \mu \mathrm{m}^{2}$, which is an order of magnitude more than that achievable by far-field methods. We expect the achievable level of sensitivity of nearfield methodology to be sufficient to tackle questions related to the distribution of molecules that are packed at physiologically relevant densities on the cell surface. We therefore anticipate that NSOM will yield results comparable to those obtained by (immunogold) transmission electron microscopy but under physiological conditions.

These intrinsic advantages of NSOM might revolutionize the life sciences. But why is NSOM hardly used in cell biology, despite its development almost two decades ago? First, as an imaging tool, NSOM is a complex technique that requires welltrained operators. Second, as we point out above, the resolution and sensitivity of a near-field microscope depend strongly on the quality of the probe aperture and the accuracy of the feedback system, necessitating full control of the technology. Moreover, the top-grade near-field microscopes are still under development in experimental physics laboratories and are therefore not widely accessible. Perhaps most important is the fact that, despite great efforts of various groups including our own, the standards set by the initial work of Betzig and Chichester cannot yet be reached in a liquid and more physiological environment. This is the technical challenge that has to be faced in the coming years.

\section{Conclusion/perspectives}

NSOM combines the high resolution of scanning probe microscopy with the contrast of optical microscopy. It can achieve single-molecule detection sensitivity on the cell surface and allows independent observation of molecules at physiologically relevant packing densities. The level of detail and sensitivity offered by this technique will be of particular value in studies of the spatial organization of the plasma membrane. Co-localization studies, a common application of far-field fluorescence imaging in cell biology, when performed by NSOM will provide unprecedented detail and accuracy, which are impossible to obtain by diffraction-limited imaging techniques. Potentially of great importance will be the application of NSOM in single-pair FRET studies combined with high-resolution imaging to study intermolecular 
A

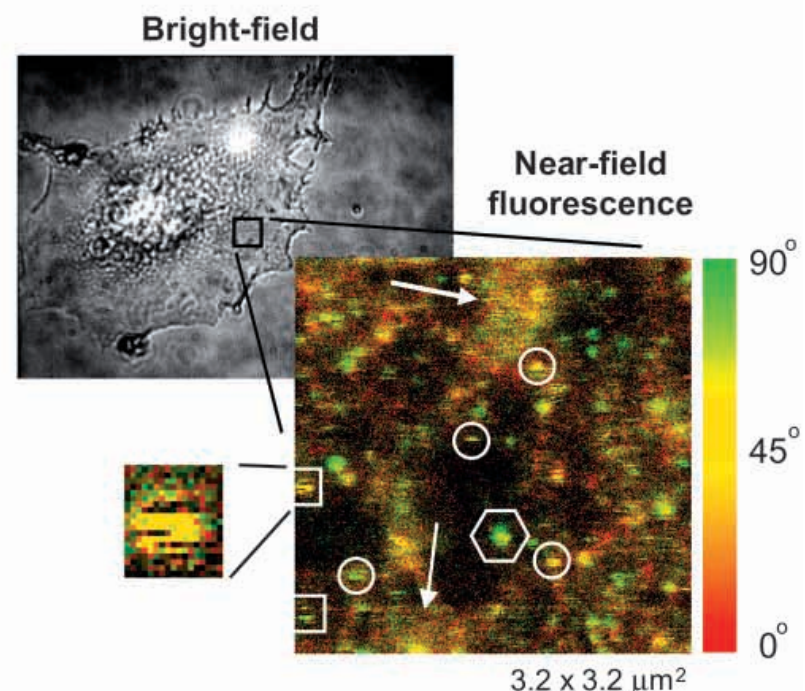

B

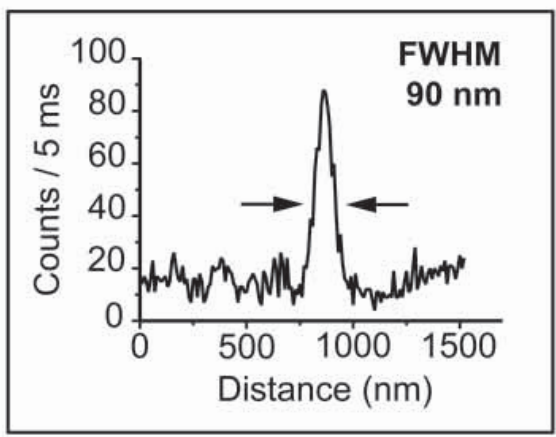

Fig. 4. (A) Single molecule detection on cells by NSOM. This figure shows a $40 \mathrm{~nm}$ optical resolution near-field 'zoom-in' on the indicated area $\left(3.2 \times 3.2 \mu \mathrm{m}^{2}\right)$ in the bright-field image of a fibroblast expressing LFA-1-GFP. GFP excitation is accomplished using $488 \mathrm{~nm}$ light (Ar-Kr laser line) linearly polarized along $90^{\circ}$. Fluorescence is collected by a 1.3 numerical aperture oil-immersion objective in combination with standard optical filters. A polarizing beam-splitter cube (Newport, Fountain Valley, CA) is used to split the fluorescence signal into two perpendicular polarized components (compare with Fig. 2). Both signals are then detected by photon-counting avalanche photodiode detectors (APD, SPCM-100, EG\&G Electro optics, Quebec). The red/green color-coding of the signals reflects the orientation of the GFP molecules in the plane of the sample. Examples of clustered molecules (arrows) as well as examples showing clear single-molecule detection sensitivity are indicated (circles and squares). The squares show the fast-blinking behavior typical of single molecule GFP fluorescence. The circles present demonstrations of discrete photodissociation phenomena. (B) Estimation of the resolution in the near-field image. This figure shows a line trace through the feature marked with the hexagon in the near-field image. The full width at half maximum (FWHM; arrows) of such traces can be used to obtain an estimate for the maximal resolution (half the FWHM) in the near-field image. On this basis, we estimate the resolution in the near-field image to be $\sim 40 \mathrm{~nm}$.

interactions or intramolecular dynamics at the single-molecule level on cells. The first such examples have already been reported (Kirsch et al., 1999); however, although clearly showing resolution below the diffraction limit, single-molecule detection sensitivity has not yet been reached. Importantly,
NSOM bridges the gap between the diffraction-limited response of normal light microscopy and the $5-10 \mathrm{~nm}$ distance sensitivity inherent in FRET and, as such, already provides important additional but otherwise unobtainable information.

In the past decade, especially the past two years, several other approaches to break the diffraction limit have been developed. These include interferometric microscopy methods such as 4Pi confocal microscopy (Hell and Stelzer, 1992), I5M (Gustafsson et al., 1999), standing-wave-total-internalreflection fluorescence microscopy (Cragg and So, 2000) and harmonic excitation light microscopy (Frohn et al., 2000). These methods, however, do not have single-molecule detection sensitivity, and all require extended electronic postprocessing of the images. Recently, a novel technique involving 'point spread function (PSF) engineering', which exploits stimulated emission depletion (STED), has been described (Klar et al., 2000). This method involves the induced quenching of fluorescence by stimulated emission at the rim of the diffraction-limited focal spot, thereby squeezing it to an almost spherical shape of $\sim 100 \mathrm{~nm}$ in diameter. Thus far, this is the only technique that seriously rivals the small excitation/detection volume and therefore sensitivity of NSOM. The maximal resolution obtained with aperture-type NSOM relates to the limited energy throughput of the nearfield probe. This limits the minimum size of the aperture to be used and hence the resolution of the microscope to $\sim 20 \mathrm{~nm}$. A possible way around this involves exploiting singlemolecule emitters, attached to a scanning probe, which act as light source to excite molecules in the sample (Michaelis et al., 2000).

The most important technical challenge that remains is the construction of an NSOM instrument that operates under physiologically relevant conditions and allows the study of soft, rough and motile surfaces, such as the plasma membrane of living cells. When combined with single-molecule detection sensitivity and an optical resolution that is comparable to transmission electron microscopy, this will prove to be an invaluable tool in cell biology. These are truly exciting times.

We thank Jeroen Korterik, Frans Segerink, Marjolein Koopman and Ben Joosten for expert technical assistance. Frank de Lange is supported by grant FB-N/T-1a from the Netherlands Foundation for Fundamental Research of Matter (FOM). Bärbel de Bakker is supported by grant TTN4812 from the Dutch Technology Foundation (STW). The research by Maria Garcia-Parajo was made possible by a fellowship of the Royal Netherlands Academy of Arts and Sciences (KNAW).

\section{References}

Allen, T. D., Cronshaw, J. M., Bagley, S., Kiseleva, E. and Goldberg, M. W. (2000). The nuclear pore complex. J. Cell Sci. 113, 3885-3886.

Ambrose, W. P., Goodwin, P. M., Martin, J. C. and Keller, R. A. (1994). Alterations of single molecule fluorescence lifetimes in near-field optical microscopy. Science 265, 364-367.

Balaban, N. Q., Schwarz, U. S., Riveline, D., Goichberg, P., Tzur, G., Sabanay, I., Mahalu, D., Safran, S., Bershadsky, A., Addadi, L. and Geiger B. (2001). Force and focal adhesion assembly: a close relationship studied using elastic micropatterned substrates. Nat. Cell Biol. 3, 466472 .

Betzig, E. and Chichester, R. J. (1993). Single molecules observed by nearfield scanning optical microscopy. Science 262, 1422-1425.

Betzig, E., Chichester, R. J., Lanni, F. and Taylor, D. L. (1993). Near-field fluorescence imaging of cytoskeletal actin. Bioimaging 1, 129-133. 
Cragg, G. E. and So, P. T. C. (2000). Lateral resolution enhancement with standing evanescent waves. Opt. Lett. 25, 46-48.

Damjanovich, S., Vereb, G., Schaper, A., Jenei, A., Matko, J., Starink, J. P., Fox, G. Q., Arndt-Jovin, D. J. and Jovin, T. M. (1995). Structural hierarchy in the clustering of HLA class I molecules in the plasma membrane of human lymphoblastoid cells. Proc. Natl. Acad. Sci. USA 92, 1122-1126.

Deniz, A. A., Dahan, M., Grunwell, J. R., Ha, T., Faulhaber, A. E., Chemla, D. S., Weiss S. and Schultz, P. G. (1999). Single-pair fluorescence resonance energy transfer on freely diffusing molecules: observation of Forster distance dependence and subpopulations. Proc. Natl. Acad. Sci. USA 96, 3670-3675.

Enderle, T., Ha, T., Ogletree, D. F., Chemla, D. S., Magowan, C. and Weiss, S. (1997). Membrane specific mapping and colocalization of malarial and host skeletal proteins in the Plasmodium falciparum infected erythrocyte by dual-color near-field scanning optical microscopy. Proc. Natl. Acad. Sci. USA 94, 520-525.

Engel, A. and Muller, D. J. (2000). Observing single biomolecules at work with the atomic force microscope. Nat. Struct. Biol. 7, 715-718.

Friedbacher, G. and Fuchs, H. (1999). Classification of scanning probe microscopics (Technical report). Pure Appl. Chem. 71, 1337-1357.

Frohn, J. T., Knapp, H. F. and Stemmer, A. (2000). True optical resolution beyond the Rayleigh limit achieved by standing wave illumination. Proc. Natl. Acad. Sci. USA 97, 7232-7236.

Frontiers in Chemistry: Single Molecules, topical issue (1999). Science 283, 1667-1695.

Garcia-Parajo, M. F., Veerman, J. A., Ruiter, A. G. and Van Hulst, N. F. (1998). Near-field optical and shear-force microscopy of single fluorophores and DNA molecules. Ultramicroscopy 71, 311-319.

Garcia-Parajo, M. F., Veerman, J. A., Segers-Nolten, G. M., de Grooth, B. G., Greve, J. and Van Hulst, N. F. (1999). Visualising individual green fluorescent proteins with a near field optical microscope. Cytometry 36, 239246.

Garcia-Parajo, M. F., Segers-Nolten, G. M., Veerman, J. A., Greve, J. and Van Hulst, N. F. (2000). Real-time light-driven dynamics of the fluorescence emission in single green fluorescent protein molecules. Proc. Natl. Acad. Sci. USA 97, 7237-7242.

Gustafsson, M. G., Agard, D. A. and Sedat, J. W. (1999). I5M: 3D widefield light microscopy with better than $100 \mathrm{~nm}$ axial resolution. J. Microsc. 195, 10-16.

Ha, T., Enderle, T., Ogletree, D. F., Chemla, D. S., Selvin, P. R. and Weiss, S. (1996). Probing the interaction between two single molecules: fluorescence resonance energy transfer between a single donor and a single acceptor. Proc. Natl. Acad. Sci. USA 93, 6264-6268.

Ha, T., Ting, A. Y., Liang, J., Caldwell, W. B., Deniz, A. A., Chemla, D. S., Schultz, P. G. and Weiss, S. (1999). Single-molecule fluorescence spectroscopy of enzyme conformational dynamics and cleavage mechanism. Proc. Natl. Acad. Sci. USA 96, 893-898.

Hansma, P. K., Cleveland J. P., Radmacher, M., Walters, D. A., Hillner, P. E., Bezanilla, M., Fritz, M., Vie, D., Hansma, H. G., Prater, C. B. et al. (1994). Tapping mode Atomic Force Microscopy in liquids. Appl. Phys. Lett. 64, 1738-1740.

Harms, G. S., Cognet, L., Lommerse, P. H., Blab, G. A. and Schmidt, T. (2001). Autofluorescent proteins in single-molecule research: applications to live cell imaging microscopy. Biophys. J. 80, 2396-2408.

Harpur, A. G., Wouters, F. S. and Bastiaens, P. I. (2001). Imaging FRET between spectrally similar GFP molecules in single cells. Nat. Biotechnol. 19, $167-169$.

Hausmann, M., Perner, B., Rapp, A., Scherthan, H. and Greulich, K.-O. (2001). NSOM imaging of labelled mitotic and meiotic chromosomes. Eur. Microsc. Anal. 71, 5-7.

Hell, S. W. and Stelzer, E. H. (1992). Properties of a 4Pi-confocal fluorescence microscope. J. Opt. Soc. Am. 9, 2159-2166.

Honda, A., Adams, S. R., Sawyer, C. L., Lev-Ram, V. V., Tsien, R. Y. and Dostmann, W. R. (2001). Spatiotemporal dynamics of guanosine 3',5'cyclic monophosphate revealed by a genetically encoded, fluorescent indicator. Proc. Natl. Acad. Sci. USA 98, 2437-2442.

Hwang, J., Gheber, L. A., Margolis, L. and Edidin, M. (1998). Domains in cell plasma membranes investigated by near-field scanning optical microscopy. Biophys. J. 74, 2184-2190.

Ishii, Y. and Yanagida, T. (2000). Single molecule detection in Life Science. Single Mol. 1, 5-13.

Ishijima, A., Kojima, H., Funatsu, T., Tokunaga, M., Higuchi, H., Tanaka, H. and Yanagida, T. (1998). Simultaneous observation of individual
ATPase and mechanical events by a single myosin molecule during interaction with actin. Cell 92, 161-171.

Johns, L. M., Levitan, E. S., Shelden, E. A., Holz, R. W. and Axelrod, D. (2001). Restriction of secretory granule motion near the plasma membrane of chromaffin cells. J. Cell Biol. 153, 177-190.

Kirsch, A. K., Subramaniam, V., Jenei, A. and Jovin, T. M. (1999). Fluorescence resonance energy transfer detected by scanning near-field optical microscopy. J. Microsc. 194, 448-454.

Kitamura, K., Tokunaga, M., Iwane, A. H. and Yanagida, T. (1999). A single myosin head moves along an actin filament with regular steps of 5.3 nanometres. Nature 397, 129-134.

Klar, T. A., Jakobs, S., Dyba, M., Egner, A. and Hell, S. W. (2000). Fluorescence microscopy with diffraction resolution barrier broken by stimulated emission. Proc. Natl. Acad. Sci. USA 97, 8206-8210.

Korchev, Y. E., Negulyaev, Y. A., Edwards, C. R., Vodyanoy, I. and Lab, M. J. (2000a). Functional localization of single active ion channels on the surface of a living cell. Nat. Cell Biol. 2, 616-619.

Korchev, Y. E., Gorelik, J., Lab, M. J., Sviderskaya, E. V., Johnston, C. L., Coombes, C. R., Vodyanoy, I. and Edwards, C. R. (2000b). Cell volume measurement using scanning ion conductance microscopy. Biophys. J. 78, 451-457.

Lehenkari, P. P., Charras, G. T., Nykanen, A. and Horton, M. A. (2000). Adapting atomic force microscopy for cell biology. Ultramicroscopy 82, 289-295.

Lippincott-Schwartz, J., Snapp, E. and Kenworthy, A. (2001). Studying protein dynamics in living cells. Nat. Rev. Mol. Cell Biol. 2, 444-456.

Llopis, J., McCaffery, J. M., Miyawaki, A., Farquhar, M. G. and Tsien, R. Y. (1998). Measurement of cytosolic, mitochondrial, and Golgi $\mathrm{pH}$ in single living cells with green fluorescent proteins. Proc. Natl. Acad. Sci. USA 95, 6803-6808.

Michaelis, J., Hettich, C., Mlynek, J. and Sandoghdar, V. V. (2000). Optical microscopy using a single-molecule light source. Nature 405, 325-328.

Miyawaki, A., Llopis, J., Heim, R., McCaffery, J. M., Adams, J. A., Ikura, M. and Tsien, R. Y. (1997). Fluorescent indicators for $\mathrm{Ca}^{2+}$ based on green fluorescent proteins and calmodulin. Nature 388, 882-887.

Miyawaki, A., Griesbeck, O., Heim, R. and Tsien, R. Y. (1999). Dynamic and quantitative $\mathrm{Ca}^{2+}$ measurements using improved cameleons. Proc. Natl. Acad. Sci. USA 96, 2135-2140.

Mochizuki, N., Yamashita, S., Kurokawa, K., Ohba, Y., Nagai, T., Miyawaki, A. and Matsuda, M. (2001). Spatio-temporal images of growthfactor-induced activation of Ras and Rap1. Nature 411, 1065-1068.

Moerner, W. E., Peterman, E. J., Brasselet, S., Kummer, S. and Dickson, R. M. (1999). Optical methods for exploring dynamics of single copies of green fluorescent protein. Cytometry 36, 232-238.

Moers, M. H., Kalle, W. H., Ruiter, A. G., Wiegant, J. C., Raap, A. K., Greve, J., de Grooth, B. G. and Van Hulst, N. F. (1996). Fluorescence in situ hybridization on human metaphase chromosomes detected by near-field scanning optical microscopy. J. Microsc. 182, 40-45.

Muller, S. A. and Engel, A. (2001). Structure and mass analysis by scanning transmission electron microscopy. Micron 32, 21-31.

Nagy, P., Jenei, A., Kirsch, A. K., Szollosi, J., Damjanovich, S. and Jovin, T. M. (1999). Activation-dependent clustering of the erbB2 receptor tyrosine kinase detected by scanning near-field optical microscopy. J. Cell Sci. 112, 1733-1741.

Neagu, C., Van der Werf, K. O., Putman, C. A., Kraan, Y. M., Van Hulst, N. F., De Grooth, B. G. and Greve, J. (1994). Analysis of immunolabeled cells by atomic force microscopy, optical microscopy and flow cytometry. J. Struct. Biol. 112, 32-40.

Patterson, G., Day, R. N. and Piston, D. (2001). Fluorescent protein spectra. J. Cell Sci. 114, 837-838.

Pohl, D. W., Denk, W. and Lanz, M. (1984). Optical stethoscopy: image recording with resolution 1/20. Appl. Phys. Lett. 44, 651-653.

Putman, C. A., Van der Werf, K. O., De Grooth, B. G., Van Hulst, N. F. and Greve, J. (1994). Tapping mode atomic force microscopy in liquid. Appl. Phys. Lett. 64, 2454-2456.

Richter, E., Hitzler, H., Zimmermann, H., Hagedorn, R. and Fuhr, G. (2000). Trace formation during locomotion of L929 mouse fibroblasts continuously recorded by interference reflection microscopy (IRM). Cell Motil. Cytoskel. 47, 38-47.

Ruiter, A. G., Veerman, J. A., Garcia-Parajo, M. F. and Van Hulst, N. F. (1997). Single molecule rotational and translational diffusion observed by near-field scanning optical microscopy. J. Phys. Chem. 101, 7318-7323.

Sako, Y., Minoghchi, S. and Yanagida, T. (2000). Single-molecule imaging of EGFR signalling on the surface of living cells. Nat. Cell Biol. 2, 168-172. 
Schmidt, T., Schutz, G. J., Baumgartner, W., Gruber, H. J. and Schindler, H. (1996). Imaging of single molecule diffusion. Proc. Natl. Acad. Sci. USA 93, 2926-2929.

Schutz, G. J., Kada, G., Pastushenko, V. P. and Schindler, H. (2000). Properties of lipid microdomains in a muscle cell membrane visualized by single molecule microscopy. EMBO J. 19, 892-901.

Simons, K. and Toomre, D. (2000). Lipid rafts and signal transduction. Nat. Rev. Mol. Cell Biol. 1, 31-39.

Smilenov, L. B., Mikhailov, A., Pelham, R. J., Marcantonio, E. E. and Gundersen, G. G. (1999). Focal adhesion motility revealed in stationary fibroblasts. Science 286, 1172-1174.

Talaga, D. S., Lau, W. L., Roder, H., Tang, J., Jia, Y., DeGrado, W. F. and Hochstrasser, R. M. (2000). Dynamics and folding of single two-stranded coiled-coil peptides studied by fluorescent energy transfer confocal microscopy. Proc. Natl. Acad. Sci. USA 97, 13021-13026.

Toomre, D. and Manstein, D. J. (2001). Lighting up the cell surface with evanescent wave microscopy. Trends Cell Biol. 11, 298-303.

Tsien, R. Y. (1998). The green fluorescent protein. Annu. Rev. Biochem. 67, 509-544.

Van Hulst, N. F. and Moers, M. H. (1996). Biological applications of nearfield scanning optical micrsocopy. IEEE Eng. Med. Biol. Mag. 15, 51-58.

Van Hulst, N. F., Veerman, J. A., Garcia-Parajo, M. F. and Kuipers, L. (2000). Analysis of individual (macro)molecules and proteins using nearfield optics. J. Chem. Phys. 112, 7799-7810.

Van Kooyk, Y. and Figdor, C. G. (2000). Avidity regulation of integrins: the driving force in leukocyte adhesion. Curr. Opin. Cell Biol. 12, 542-547.

Van Oijen, A. M., Köhler, J., Schmidt, J., Müller, M. and Brakenhoff, G. J. (1998). 3-Dimensional super-resolution by spectrally selective imaging. Chem. Phys. Lett. 292, 183-187.
Van Oijen, A. M., Ketelaars, M., Kohler, J., Aartsma, T. J. and Schmidt, J. (1999). Unraveling the electronic structure of individual photosynthetic pigment-protein complexes. Science 285, 400-402.

Vickery, S. A. and Dunn, R. C. (2001). Combining AFM and FRET for high resolution fluorescence microscopy. J. Microsc. 202, 408-412.

Weiss, S. (1999). Fluorescence spectroscopy of single biomolecules. Science. 283, 1676-1683.

Willemsen, O. H., Snel, M. M., Cambi, A., Greve, J., De Grooth, B. G. and Figdor, C. G. (2000). Biomolecular interactions measured by atomic force microscopy. Biophys. J. 79, 3267-3281.

Woolley, A. T., Guillemette, C., Li Cheung, C., Housman, D. E. and Lieber, C. M. (2000). Direct haplotyping of kilobase-size DNA using carbon nanotube probes. Nat. Biotechnol. 18, 760-763.

Wouters, F. S., Verveer, P. J. and Bastiaens, P. I. (2001). Imaging biochemistry inside cells. Trends Cell Biol. 11, 203-211.

Xie, X. S. and Dunn, R. C. (1994). Probing single molecule dynamics. Science 265, 361-364.

Xie, X. S. and Lu, H. P. (1999). Single-molecule enzymology. J. Biol. Chem. 274, 15967-15970

Yarden, Y. and Schlessinger, J. (1987a). Self-phosphorylation of epidermal growth factor receptor: evidence for a model of intermolecular allosteric activation. Biochemistry 26, 1434-1442.

Yarden, Y. and Schlessinger, J. (1987b). Epidermal growth factor induces rapid, reversible aggregation of the purified epidermal growth factor receptor. Biochemistry 26, 1443-1451.

Zaccolo, M., De Giorgi, F., Cho, C. Y., Feng, L., Knapp, T., Negulescu, P. A., Taylor, S. S., Tsien, R. Y. and Pozzan, T. (2000). A genetically encoded, fluorescent indicator for cyclic AMP in living cells. Nat. Cell Biol. 2, 25-29. 